\title{
Does preoperative administration of allopurinol protect the lungs from ischemia-reperfusion injury occuring during cardiopulmonary bypass?
}

\author{
Gormus ZI ${ }^{1}$, Celik $\mathrm{JB}^{2}$, Ergene $\mathrm{N}^{3}$, Gormus $\mathrm{N}^{4}$, Baltaci $\mathrm{AK}^{5}$ \\ Blood Donation Center, Selcuklu Medical School, University of Selcuk, Konya, Turkey. baltaci@selcuk.edu.tr
}

\begin{abstract}
Background: It is investigated whether preoperative allopurinol administration protects lung injury induced by cardiopulmonary bypass (CPB).

Methods: Sixty patients with coronary artery disease who need elective coronary artery bypass grafting operations by using CPB were taken into this study. They were divided into two groups; control and allopurinol. Allopurinol (300 mg/day) was administered to the latter group during the preoperative period of 5 days. Standard CPB procedures were used in all cases. Blood was sampled for TNF-alpha, IL-6, IL-8, IL-10 before anesthesia (T0), after anesthesia and before skin incision (T1), before CPB (T2), after aortic declamping (T3), at the end of CPB (T4), 6 hours after operation (T5), 12 hours after operation (T6), and 24 hours after operation (T7). Pulmonary function test (PFT) was performed before and following the 6th day of operation.

Results: TNF-alpha, IL-6, IL-8 increased in both groups at T3, T4, T5 and T6 compared to control $(p<0.05)$. TNF-alpha, IL-6, and IL-8 levels were lower in group A at T3, T4, T5 and T6 $(p<0.05)$. Creatinin phosphokinase $(C K)$ levels were lower in group A at T6 $(p<0.05)$. CK-MB levels were lower in group A than in group C $(p<0.05)$. Pulmonary function test (PFT) did not yield any differences between the groups.

Conclusions: Preoperative allopurinol administration decreases the inflammation and myocardial injury according to biochemical markers of ischemia reperfusion injury. However, this biochemical success does not rebound to PFT (Tab. 5, Ref. 15). Full Text in PDF www.elis.sk.

Key words: cardiopulmonary bypass, lung, ischemia-reperfusion injury, allopurinol.
\end{abstract}

Cardiopulmonary bypass (CPB) circuits initiate a severe systemic inflammatory response. Ischemia-reperfusion, surgical trauma and endotoxemia are the other main causes of this systemic inflammatory response. It has been reported that this systemic inflammatory response is clinically characterized by pathological hypotension, fever of unknown origin, disseminated intravascular coagulation (DIC), diffuse tissue edema, injury, and multiple organ failure (1-3).

Cardiopulmonary bypass-induced complex of inflammatory response is associated with activation and accumulation of polymorphonuclear leukocytes (PMNL). The PMNLs adhere along the endothelium and migrate into the tissue by transendothelial way. Soluble adhesion molecules such as tumor necrosis factor-alpha (TNF-alpha), interleukin-6 (IL-6), IL-8, and IL-10 that are placed

${ }^{1}$ Blood Donation Center, Selcuklu Medical School, University of Selcuk, Konya, ${ }^{2}$ Anesthesiology and Intensive Care, Meram Medical School, University of Selcuk, Konya, ${ }^{3}$ Departments of Physiology, Meram Medical School, University of Selcuk, Konya, ${ }^{4}$ Department of Cardiovascular Surgery, Meram Medical School, University of Selcuk, Konya, Turkey, and ${ }^{5}$ Department of Physiology, Selcuklu Medical School, University of Selcuk, Konya, Turkey

Address for correspondence: A.K. Baltaci, MD, Department of Physiology, Selcuklu Medical School, University of Selcuk, Campus, 42075, Selcuklu, Konya, Turkey.

Acknowledgement: This prospective study has been presented as a poster presentation at "The 37th IUPS International Congress of Physiological Sciences", in Kyoto, Japan 27th July - 1st August 2009. on the surface of these activated leukocytes, platelets, and endothelium mediate these interactions $(1-4)$. These soluble adhesion molecules have been found in the peripheral blood and may serve as markers of cardiopulmonary bypass-induced complex inflammatory response and postoperative multiple organ dysfunction (1). TNF-alpha, IL-6, IL-8, and IL-10 have been used in many clinical and experimental studies in order to project the inflammatory response seen after cardiopulmonary bypass (1-6). There are rnany reports about the medications in order to avoid the inflammatory response and associated multiorgan injury. Pentoxyphylline, aprotinin, and allopurinol are the most commonly investigated medications for this purpose. Allopurinol is a competitive inhibitor of xanthine oxidase and is a radical scavenger (4-6). However, these studies mainly investigated the possible protective role of preoperative allopurinol administration on myocardial injury. In the present study we aimed to investigate whether preoperative allopurinol administration prevents the lung injury following cardiopulmonary bypass.

\section{Methods}

\section{Patient selection}

After local ethics committee approval and informed consent, 60 patients were selected for operation according to American College of Cardiology guidelines for coronary artery bypass grafting 
Tab. 1. Pre-perioperative characteristics of patients in both groups. Data are presented as mean $( \pm \mathrm{SD})$ for continuous variables and numbers for categorical variables.

\begin{tabular}{lcc}
\hline & $\begin{array}{c}\text { Group C } \\
(\mathrm{n}=30)\end{array}$ & $\begin{array}{c}\text { Group A } \\
(\mathrm{n}=30)\end{array}$ \\
\hline Age (year) & $59( \pm 9)$ & $62( \pm 7)$ \\
Height $(\mathrm{cm})$ & $165( \pm 7)$ & $169( \pm 9)$ \\
Weight $(\mathrm{kg})$ & $87( \pm 9)$ & $82( \pm 8)$ \\
NYHA Class $(2 / 3 / 4)$ & $10 / 11 / 9$ & $19 / 9 / 11$ \\
Hypertension (no/yes) & $11 / 19$ & $11 / 19$ \\
Smoker (no/yes) & $8 / 22$ & $7 / 23$ \\
Number of affected vessels & $3( \pm 0.7)$ & $2.9( \pm 0.7)$ \\
Ejection fraction $(\%)$ & $52( \pm 9)$ & $56( \pm 8)$ \\
Operation time (min) & $236( \pm 11)$ & $228( \pm 16)$ \\
CPB time (min) & $95( \pm 9)$ & $92( \pm 14)$ \\
Aortic cross clamp time (min) & $67( \pm 10)$ & $71( \pm 9)$ \\
Intraoperative fluid intake (ml/kg) & $62( \pm 9)$ & $65( \pm 9)$ \\
\hline NYHA - New York Heart Association Classification &
\end{tabular}

NYHA - New York Heart Association Classification

(CABG). The patients were free from pulmonary disease and had normal standard chest radiographs. Patients who had an associated valve disease, and those using corticosteroid drugs, pentoxyfilline or allopurinol for a long-period (for gout disease) were excluded from the study. There were no significant differences between the groups in terms of age, height, weight, preoperative ejection fraction (Tab. 1). The patients were divided into two equal groups, namely group $\mathrm{C}$ (control, $\mathrm{n}=30$ ) and group A (allopurinol, $\mathrm{n}=30$ ). Allopurinol (300 mg/daily, Ilsan Iltas, Turkey) was administered to patients of group A during the preoperative period of 5 days. Pulmonary function test was performed in all patients before the operation (also before administration of allopurinol in group A) and on 7 th postoperative day. FVC and FEV measurements were compared among the groups and between the pre-postoperative measurements of each group.

\section{Anesthesia procedure}

The intraoperative anesthesia procedure was standardized in both groups and consisted of intravenous fentanyl $(20 \mu \mathrm{g} / \mathrm{kg})$, midazolam (10 mg total) and vecuronium $(0.1 \mathrm{mg} / \mathrm{kg})$. Patients were ventilated with oxygen/air (inspired oxygen fraction 0.5 ) with a tidal volume of $5-7.5 \% \mathrm{ml} / \mathrm{kg}$ at normocapnia. All of the fentanyl was administered before sternotomy. Regarding midazolam, $6 \mathrm{mg}$ was administered before sternotomy, $2 \mathrm{mg}$ during rewarming and $2 \mathrm{mg}$ during sternal closure. If required, inhaled sevoflurane was used before the initiation of CPB.

\section{Operation procedure}

A standard cardiopulmonary bypass procedure was undertaken with moderate hypothermia $\left(32^{\circ} \mathrm{C}\right)$, and a nonpulsatile flow from membrane oxygenator (Dideco 708, Italy). Priming volume consisted of 2 liters of Ringer's solution. Non-pulsatile flows were maintained between 2.4 and $2.81 / \mathrm{min} / \mathrm{m}^{2}$, and mean arterial pressure was kept in range of 50-70 $\mathrm{mmHg}$. During CPB, the lungs were not ventilated. Cold-blood antegrade cardioplegia and hotshot blood cardioplegia before removing the aortic cross-clamp were used in all patients. The single aortic cross-clamp technique was preferred in all operations. Left internal thoracic artery and one or two peripheral vein grafts (taken from the great saphenous veins) were used. Operation times, CPB times, and aortic occlusion periods did not differ between the groups (Tab. 1).

\section{Sample collection and measurements}

Blood samples for measurements of TNF-alpha, IL-6, IL-8, IL-10 were taken as follows: before anesthesia (T0), after anesthesia and before skin incision (T1), before CPB (T2), after aortic declamping (T3), at the end of CPB (T4), 6 hours after operation (T5), 12 hours after operation (T6), and 24 hours after operation (T7). Blood samples were collected in phlebotomy tubes containing ethylene diamine tetraacetic acid. Platelet-poor plasma was prepared by centrifuging at 3,000 g for 10 minutes. The plasma was stored in propylene tubes at $-80{ }^{\circ} \mathrm{C}$ until assay. TNF-alpha, IL-6, IL-8, IL-10 were measured in all samples with enzymelinked immunosorbent assay kits (ELISA; Immulite, DPC, Los Angeles; USA). Analysis of cardiac enzymes in blood specimens was also made. Total serum activity of creatinin kinase (CK) was determined by enzymatic method, and the activity of MB isoenzyme creatine kinase (CK-MB) was quantified by the immunoassay method (Doehringer, Mannheim, Germany). CK and CKMB were evaluated at intervals as follows: T0, T4, and T5. Arterial blood gas samples for $\mathrm{pH}$, lactate, base excess (BE), $\mathrm{pO}_{2}, \mathrm{pCO}_{2}$ were evaluated at the same time as samples were taken for TNF-alpha, IL-6, IL-8, IL-10.

\section{Pulmonary function test}

In all patients, pulmonary function tests were performed before the operation and on 7 th postoperative day by means of spirometry (Vmax 22, 1998, California, USA). In these tests, the results of forced expiratory volume $\left(\mathrm{FEV}_{1}\right)$ and forced vital capacity (FVC) were recorded for statistical analysis in both groups.

\section{Statistical analysis}

Calculations of data were performed on a personal computer using SPSS version 10.0. Student's t test (or Mann-Whitney U-test, where appropriated) was used to test the difference between means in two groups regarding demographic and clinical characteristics of patients and perioperative data. Fisher exact test was used for categorical data. To account for arterial blood gases, cytokines, cardiac enzymes, repeated-measures analysis of variance (ANOVA) was used. ANOVA and chi square tests were used for statistical analysis of $\mathrm{FVC}$ and $\mathrm{FEV}_{1}$ results. A $p$ value less than 0.05 was regarded statistically significant.

\section{Results}

There were no deaths in either of groups. Preoperative and intraoperative characteristics of patients in both groups are given in Table 1. There were no significant differences among the groups according to these parameters. The arterial blood gas analysis $\left(\mathrm{pH}, \mathrm{pCO}_{2}, \mathrm{pO}_{2}, \mathrm{FICO}_{3}, \mathrm{BE}\right.$, lactate) was similar between groups $\mathrm{C}$ and $\mathrm{A}$.

In both $\mathrm{C}$ and $\mathrm{A}$ groups, patients were extubated within 24 hours after their arrival to the intensive care unit (ICU). Table 2 
Tab. 2. Postoperative data of patients in both groups.

\begin{tabular}{lcc}
\hline Parameters & Group C & Group A \\
\hline Minimum respiratory rate $(\mathrm{bpm})$ & $10( \pm 1)$ & $9( \pm 1)$ \\
Maximum respiratory rate $(\mathrm{bpm})$ & $19( \pm 2)$ & $16( \pm 3)$ \\
Minimum temperature $\left({ }^{\circ} \mathrm{C}\right)$ & $36( \pm 0.9)$ & $35.2( \pm 0.7)$ \\
Maximum temperature $\left({ }^{\circ} \mathrm{C}\right)$ & $38.5( \pm 0.6)$ & $37( \pm 0.2)$ \\
Time to tracheal extubation (min) & $514( \pm 36)$ & $526( \pm 34)$ \\
Length of stay in ICU (h) & $42.1( \pm 3.7)$ & $35.7( \pm 4.7)$ \\
Length of stay in hospital (day) & $12.4( \pm 2.3)$ & $11.2( \pm 1.3)$ \\
Incidence of arrhytmia (n) & 12 & 11 \\
Incidence of MI (n) & 2 & 1 \\
\hline
\end{tabular}

* $\mathrm{p}<0.05$; statistically significant difference between groups. Data are reported as mean $( \pm \mathrm{SD})$. ICU - intensive care unit, MI - myocardial infarction

demonstrates the postoperative characteristics of patients in both groups. Among these parameters only the length of stay in ICU (h) was shorter in group A (35.7 \pm 4.7$)$ than in group C (42.1 \pm 3.7$)$ $(\mathrm{p}<0.05)$.

\section{Cytokines}

TNF-alpha, IL-6 and IL-8 increased significantly in both groups at T3, T4, T5 and T6 when compared to control values $(p<0.05)$. Concentrations of TNF-alpha, IL-6 and IL-8 were significantly lower in group A than in group C at T3, T4, T5 and T6 (Tab. 3) $(\mathrm{p}<0.05)$.

In comparison to the control value, the concentration of IL10 increased in groups A and C from T3 to T6 $(\mathrm{p}<0.05)$. IL-10, which is considered to be a potent anti-inflammatory cytokine, significantly increased in group A when compared to group $\mathrm{C}$ at T3, T4, and T6 $(\mathrm{p}<.0 .05)$.

\section{Cardiac enzymes}

There were no perioperative and postoperative myocardial infarctions in either group. Plasma CK and CK-MB levels were
Tab. 5. Pre-postoperative results of FEV and FVC in both groups (mean \pm SD).

\begin{tabular}{lcccc}
\hline & Preop FEV & Postop FEV & Preop FVC & Postop FVC \\
\hline Group C & $83 \pm 19.3$ & $59.3 \pm 17.3$ & $80.1 \pm 12.6$ & $54.1 \pm 17.3$ \\
Group A & $86.4 \pm 18.7$ & $63 \pm 9$ & $87.4 \pm 12.6$ & $86.4 \pm 18.7$ \\
\hline
\end{tabular}

significantly increased in both groups at T5, T6, and T7 $(\mathrm{p}<0.05)$. Comparison of plasma CK levels showed that values were significantly lower in group A than in group $\mathrm{C}$ at $\mathrm{T} 6(\mathrm{p}<0.05)$. The plasma CK-MB levels were significantly lower in group A than in group $C(p<0.05)$ (Tab. 4). These results showed that allopurinol administration decreases the myocardial injury that occurs during cardiopulmonary bypass.

\section{$F E V_{1}-F V C$}

The results are given as mean $+\mathrm{SD}$ values in Table 5. Statistical analysis showed no significant differences between the groups and also between the preoperative and postoperative measurements $(p>0.05)$. This may be due to the limited number of patients.

\section{Discussion}

Cardiopulmonary bypass is the most preferred technique among all cardiac operations. Although technical advances have improved the safety of CPB, it is associated with mortality and morbidity due to biological response of the body to artificial perfusion and gas exchange through the non-endothelialized CPB circuit. When CPB initiates, the formed and unformed blood elements come into contact with the large surface area of this artificial circuit. This contact causes extensive activation of platelets, neutrophils, complements, cytokines, and the fibrinolytic system which are all responsible for producing a complex and intense

Tab. 3. Plasma cytokine values (mean \pm SD).

\begin{tabular}{|c|c|c|c|c|c|c|c|c|c|}
\hline Cytokines & & T0 & $\mathrm{T} 1$ & $\mathrm{~T} 2$ & T3 & T4 & T5 & T6 & $\mathrm{T} 7$ \\
\hline \multirow[t]{2}{*}{ TNF-alpha (pg.ml) } & Group A & $3.1 \pm 1.2$ & $5.2 \pm 1.7$ & $6.0 \pm 1.8$ & $12.1 \pm 2.7 *$ & $10.6 \pm 3.5 * \#$ & $11.7 \pm 2.8 * \#$ & $6.5 \pm 3.2 * \#$ & $3.8 \pm 2.7$ \\
\hline & Group C & $3.2 \pm 2.1$ & $5.8 \pm 1.6$ & $6.5 \pm 1.3$ & $21.36 \pm 3.2 * \#$ & $23.2 \pm 7.6^{* \#}$ & $18.2 \pm 3.2 * \#$ & $16.6 \pm 4.8 * \#$ & $4.2 \pm 2.6$ \\
\hline \multirow[t]{2}{*}{ IL-6 (pg.ml) } & Group A & $6.2 \pm 1.7$ & $8.7 \pm 4.1$ & $9.6 \pm 3.2$ & $25.7 \pm 3.2 * \#$ & $39.9 \pm 4.8 * \#$ & $36.2 \pm 2.8 *$ & $19.2 \pm 5.2 * \#$ & $7.7 \pm 2.3$ \\
\hline & Group C & $6.4 \pm 1.3$ & $8.2 \pm 3.9$ & $10.6 \pm 2.8$ & $53.6 \pm 9.2 * \#$ & $86.1 \pm 4.8 * \#$ & $36.8 \pm 9.2$ & $28.6 \pm 8.6 * \#$ & $8.6 \pm 2.4$ \\
\hline IL-8 (pg.ml) & Group A & $2.8 \pm 0.5$ & $3.1 \pm 1.0$ & $3.5 \pm 1.1$ & $5.5 \pm 1.7 * \#$ & $9.1 \pm 2.1 * \#$ & $7.6 \pm 2.1 * \#$ & $7.9 \pm 1.8 * \#$ & $2.7 \pm 0.5$ \\
\hline \multirow[t]{2}{*}{ IL-10 (pg.ml) } & Group A & $4.1 \pm 1.1$ & $5.0 \pm 1.2$ & $5.0 \pm 1.2$ & $51.6 \pm 5.2 * \#$ & $120.6 \pm 3.2 *$ & $40.6 \pm 3.2 *$ & $54.2 \pm 7.6 * \#$ & $25.1 \pm 3.1$ \\
\hline & Group C & $3.4 \pm 1.2$ & $5.1 \pm 0.8$ & $5.9 \pm 1.4$ & $42.4 \pm 9.2 * \#$ & $50.2 \pm 6.1 * \#$ & $33.6 \pm 6.5^{*}$ & $36.2 \pm 7.8^{* \#}$ & $19.2 \pm 4.1$ \\
\hline
\end{tabular}

* statistically significant according to control values, \# statistically significant difference between the groups, $\mathrm{p}<0.05$

Tab. 4. Plasma CK- and CK-MB levels.

\begin{tabular}{|c|c|c|c|c|c|}
\hline Cardiac enzymes & & $\mathrm{T} 0($ mean $\pm \mathrm{SD})$ & $\mathrm{T} 5($ mean $\pm \mathrm{SD})$ & T6 $($ mean $\pm \mathrm{SD})$ & $\mathrm{T} 7($ mean $\pm \mathrm{SD})$ \\
\hline \multirow[t]{2}{*}{$\overline{\mathrm{CK}}(\mathrm{IU} / \mathrm{L})$} & Group A & $40.6 \pm 8.2$ & $386.2 \pm 7.1 *$ & $301.6 \pm 5.2^{*+}$ & $112.4 \pm 6.5^{*}$ \\
\hline & Group C & $38.7 \pm 6.9$ & $413.4 \pm 8.6^{*}$ & $402.4 \pm 6.8^{*+}$ & $116.2 \pm 7.9 *$ \\
\hline \multirow[t]{2}{*}{ CK-MB (IU/L) } & Group A & $4.1 \pm 1.6$ & $32.6 \pm 1.8^{*+}$ & $30.6 \pm 2.4^{*+}$ & $8.2 \pm 2.8$ \\
\hline & Group C & $3.5 \pm 0.8$ & $42.5 \pm 0.8^{*+}$ & $46.8 \pm 9.2^{*+}$ & $8.6 \pm 3.1 *$ \\
\hline
\end{tabular}

* statistically significant difference according to control value, + statistically significant difference between the groups, ${ }^{*+} \mathrm{p}<0.05$ 
inflammatory response. Beyond this systemic inflammatory response, sternotomy, harvesting of the internal thoracic artery and pleurotomy may cause pulmonary dysfunction arter CPB. Bund et al (7) investigated the pulmonary function before and after CPB by using blood gas analysis and side-stream spirometry in 18 patients. They demonstrated a substantial reduction in the dynamic compliance of respiratory system after CPB, which leads to an increased work of breathing and increased myocardial work. Alat et al (8) reported the pulmonary effects of CPB by observing the changes in bronchoalveolar lavage fluids. They investigated the cell contents of bronchoalveolar lavage fluid, alveolar macrophage viability, eosinophil cationic protein levels and myeloperoxidase concentrations in samples of bronchoalveolar lavage fluids. When they compared the preoperative samples with samples taken $20 \mathrm{~h}$ after the termination of $\mathrm{CPB}$, they found statistically significant increases in alveolar macrophages $(p=0.028)$, neutrophil percentages $(\mathrm{p}=0.036)$, and myeloperoxidase levels $(\mathrm{p}=0.039)$. Histopathological studies in the lung alveoli after CPB demonstrated that CPB causes extensive injury to air-blood barrier, swelling or necrotic changes of type 1 pneumocytes and endothelial cells. Moreover it was seen that in many alveoli, the pulmonary surfactant could not cover the alveolar surface because of edema.

It is well documented that CPB causes a decrease in partial arterial oxygen pressure with $100 \%$ inspired oxygen in the postoperative period, significant postoperative increase in the alveolararterial oxygen gradient, and finally, an increase in postoperative pulmonary shunts (8). These findings have led the investigators to search and find a new drug or technique which might reduce the pulmonary injury that occurs during CPB procedure. In a study carried out by Horton et al (9), they covered the circulatory area of the CPB circuit by albumin and/or heparin in order to decrease the systemic inflammation caused by the contact of blood and blood components with foreign surface during CPB. Statistically significant differences were found neither clinically nor biochemically, and they concluded that none of these agents was successfull. Same results have been demonstrated by Defraigne et al (10).

Nowadays, in coronary artery bypass grafting operation performed on patients with chronic obstructive pulmonary diseases, the off-pump coronary artery bypass (OPCAB) operation is the preferred technique as it does not cause organ insufficiencies seen in $\mathrm{CPB}$. When compared to $\mathrm{CPB}$, the OPCAB operation provides some advantages such as earlier recovery, better postoperative pulmonary function, patient comfort, as well as earlier discharge from hospital $(3,11)$. In this study, OPCAB patients were excluded.

Intraoperative blood salvage devices allow a reinfusion of red blood cells (RBCs) after processing of shed blood and stagnant blood in the mediastinal cavity. These devices have been shown to reduce homologous blood requirements in cardiac surgery with CPB. It is well known that the proinflammatory activity of shed blood also contributes to morbidity during CPB. Amand et al (12) conducted a prospective study in order to examine the quality of autologous blood before and after processing with five different devices [BRAT2, Sequestra, Compact Advanced, Cell Saver 5 (CS5), Continuous Autologous Transfusion System (CATS)]. They noted the attenuation rates of IL-6 and TNFalpha (95\%) were optimal for all investigated blood salvage systems. Regarding IL-8, only the CATS and CS5 systems were able to attenuate this biological parameter with excellent efficacy. The rates of attenuation in MPO and elastase, as markers of leukocyte activation, were higher than $80 \%$ for all devices. In an experimental study conducted on pigs, in order to prevent lung injury during CPB, Carney et al (13) used chemically modified tetracycline (CMT-3), a potent elastase and matrix metalloproteinase inhibitor. They noted that all pathological changes of acute lung injury that occured during $\mathrm{CPB}$ were avoided in the study group. In CABG operations Richter et al (14) developed a system (Drew-Anderson technique), in which the patients used their own lungs as the oxygenator. By this, they reported that pulmonary and other organ damages caused by systemic inflammation during CPB were seen least. The advance in technology has provided new minimal extracorporeal circulation methods. This method contains a centrifugal pump, oxygenator and modified suction system. Immer et al (15) reported that the use of this mini circulation system decreased the ischemic myocardial injury when compared with classical CPB circuits. In another study using a resembling method and two extracorporeal circulation lines performed without an oxygenator method, it was reported that the inflammatory response seen in the pulmonary bed decreased after the removal of aortic cross-clamping. However, since two circulation lines are used, this may cause confusion and narrowing of the operation field.

In the present study it has been shown that $\mathrm{CPB}$ circuit initiates a severe inflammatory response as shown before. TNF-alpha, IL-6, and IL-8 levels significantly increased in both groups when compared to baseline values. In allopurinol administered groups, the levels of these inflammatory cytokines were significantly lower than in the control group. Conversely, the levels of IL-10, a potent anti-inflammatory cytokine, were significantly increased by allopurinol administration. Nonetheless, no significant differences were observed in pulmonary function tests.

\section{References}

1. Warren OJ, Smith AJ, Alexiou C, Rogers PL, Jawad N, Vincent C, Darzi AW, Athanasiou T. The inflammatory response to cardiopulmonary bypass: Part 1- Mechanisms of pathogenesis. J Cardiothorac Vasc Anesth 2009; 23 (2): 223-231.

2. Paparella D, Yau TM, Young E. Cardiopulmonary bypass induced inflammation: pathophysiology and treatment. An update. Eur J Cardiothorac Surg 2002; 21 (2): 232-244.

3. Larmann J, Theilmeier G. Inflammatory response to cardiac surgery: cardiopulmonary bypass versus non-cardiopulmonary bypass surgery. Best Pract Res Clin Anaesthesiol 2004; 18 (3): 425-438.

4. Tarkka MR, Vuolle M, Kaukinen S, Holm P, Eloranta J, Kaukinen U, Sisto T, Kataja J. Effect of allopurinol on myocardial oxygen free radical production in coronary bypass surgery. Scand Cardiovasc J 2000; 34 (6): 593-596. 
5. Angdin M, Settergren G, Starkopf J, Zilmer M, Zilmer K, Vaage J. Protective effect of antioxidants on pulmonary endothelial function after cardiopulmonary bypass. J Cardiothorac Vasc Anesth 2003; 17 (3): 314-320.

6. Talwar S, Sandeep JA, Choudhary SK, Velayoudham D, Lakshmy R, Kasthuri JM, Kumar AS. Effect of preoperative administration of allopurinol in patients undergoing surgery for valvular heart diseases. Eur J Cardiothorac Surg 2010; 38 (1): 86-90.

7. Bund M, Seitz W, Uthoff K, Krieg P, Strüber M, Piepenbrock S. Monitoring of respiratory function before and after cardiopulmonary bypass using side-stream spirometry. Eur J Anaesthesiol 1998; 15 (1): 44-49.

8. Alat I, Yüksel M, Büket S, Nalbantgil S, Aşkar F, Bayindir U, Taşbakan S, Kokuludag A, Veral A. The side-effects of cardiopulmonary bypass on the lungs: changes in bronchoalveolar lavage fluids. Perfusion 2001; 16 (2): 121-128.

9. Horton SB, Butt WW, Mullaly RJ, Thuys CA, O'Connor EB, Byron K, Cochrane AD, Brizard CP, Karl TR. IL-6 and IL-8 levels after cardiopulmonary bypass are not affected by surface coating. Ann Thorac Surg 1999; 68 (5): 1751-1755.

10. Defraigne JO, Pincemail J, Larbuisson R, Blaffart F, Limet R. Cytokine release and neutrophil activation are not prevented by heparincoated circuits and aprotinin administration. Ann Thorac Surg 2000; 69 (4): 1084-1091.
11. Quaniers JM, Leruth J, Albert A, Limet RR, Defraigne JO. Comparison of inflammatory responses after off-pump and on-pump coronary surgery using surface modifying additives circuit. Ann Thorac Surg 2006; 81 (5): 1683-1690.

12. Amand T, Pincemail J, Blaffart F, Larbuisson R, Limet R, Defraigne JO. Levels of inflammatory markers in the blood processed by autotransfusion devices during cardiac surgery associated with cardiopulmonary bypass circuit. Perfusion 2002; 17 (2): 117-123.

13. Carney DE, Lutz CJ, Picone AL, Gatto LA, Ramamurthy NS, Golub LM, Simon SR, Searles B, Paskanik A, Snyder K, Finck C, Schiller HJ, Nieman GF. Matrix metalloproteinase inhibitor prevents acute lung injury after cardiopulmonary bypass. Circulation 1999; 100 (4): 400-406.

14. Richter JA, Meisner H, Tassani P, Barankay A, Dietrich W, Braun SL. Drew-Anderson technique attenuates systemic inflammatory response syndrome and improves respiratory function after coronary artery bypass grafting. Ann Thorac Surg 2000; 69 (1): 77-83.

15. Immer FF, Pirovino C, Gygax E, Englberger L, Tevaearai H, Carrel TP. Minimal versus conventional cardiopulmonary bypass: assessment of intraoperative myocardial damage in coronary bypass surgery. Eur J Cardiothorac Surg 2005; 28 (5): 701-704.

Received October 17, 2011. Accepted July 20, 2013. 